\title{
Impact of the COVID-19 pandemic on the human resources for
}

\section{health in India and key policy areas to build a resilient health}

\section{workforce [version 1; peer review: 1 approved, 2 approved}

\section{with reservations]}

\author{
Ankita Mukherjee (D), Rakesh Parashar (iD) \\ Oxford Policy Management, New Delhi, 110049, India
}

V1 First published: 15 Oct 2020, 4:159

https://doi.org/10.12688/gatesopenres.13196.1

Latest published: 15 Oct 2020, 4:159

https://doi.org/10.12688/gatesopenres.13196.1

\begin{abstract}
The COVID-19 pandemic has disrupted the already low resourced, fragmented and largely unregulated health systems in countries like India. It has only further exacerbated the stress on human resources for health $(\mathrm{HRH})$ in many unanticipated ways. We explored the effect of COVID-19 pandemic on the health workforce in India, and analytically extrapolated the learnings to draw critical components to be addressed in the HRH policies, which can further be used to develop a detailed 'health workforce resilience' policy. We examined the existing literature and media reports published during the pandemic period, covering the gaps and challenges that impeded the performance of the health workers. Recommendations were designed by studying the learnings from various measures taken within India and in some other countries. We identified seven key areas that could be leveraged and improved for strengthening resilience among the health workforce. The system-level factors (at macro level) include developing a health workforce resilience policy, planning and funding for emergency preparedness, stakeholder engagement and incentivization mechanisms; the organization-level factors (meso level) include identifying $\mathrm{HRH}$ bench strength, mobilizing the health workforce, psycho-social support, protection from disease; and the individual-level factors (micro level) include measures around self-care by health workers. In keeping with the interdisciplinary nature of the associated factors, we emphasize on developing a future-ready health workforce using a multi-sectoral approach for building its strength and resilience.
\end{abstract}

\section{Keywords}

health systems, resilience, health crisis, COVID-19, human resource for health, health workers, policy framework, health resilience framework 
This article is included in the Coronavirus

(COVID-19) collection.

Corresponding author: Ankita Mukherjee (ankita085@gmail.com)

Author roles: Mukherjee A: Conceptualization, Visualization, Writing - Original Draft Preparation; Parashar R: Conceptualization, Visualization, Writing - Review \& Editing

Competing interests: No competing interests were disclosed.

Grant information: This work was supported by the Bill \& Melinda Gates Foundation [INV-007989].

The funders had no role in study design, data collection and analysis, decision to publish, or preparation of the manuscript.

Copyright: @ 2020 Mukherjee A and Parashar R. This is an open access article distributed under the terms of the Creative Commons Attribution License, which permits unrestricted use, distribution, and reproduction in any medium, provided the original work is properly cited.

How to cite this article: Mukherjee A and Parashar R. Impact of the COVID-19 pandemic on the human resources for health in India and key policy areas to build a resilient health workforce [version 1; peer review: 1 approved, 2 approved with reservations] Gates Open Research 2020, 4:159 https://doi.org/10.12688/gatesopenres.13196.1

First published: 15 Oct 2020, 4:159 https://doi.org/10.12688/gatesopenres.13196.1 


\section{Disclaimer}

The views expressed in this article are those of the author(s). Publication in Gates Open Research does not imply endorsement by the Gates Foundation.

\section{Background}

It is likely that most low and middle-income countries would fail to meet the health workforce requirements for providing advanced preventive and curative healthcare to all their citizens in the near future. The COVID-19 pandemic has once again highlighted the dismal reality of our health systems globally, and it calls for a paradigm shift in the health systems resourcing and policies. Although COVID-19 is being prioritised and all resources are directed towards its mitigation, it is also crucial to appreciate the burden of other acute and chronic illnesses, that are being neglected, for which we would require our 'human resources for health' (HRH) in its best armour.

India, with a total number of COVID-19 confirmed cases of 6.15 million as of $29^{\text {th }}$ September 2020, has recorded nearly 96,000 deaths ${ }^{1}$. India's weak 'human resources for health' (HRH) capacity and its inadequate deployment strategies could have been major contributors to the poor containment of the spread of the pandemic, in the country. The HRH includes all clinical, management and support staff related to health service delivery. Although there has been substantial growth in the number of health workers recently in India, the health workforce remains chronically insufficient (in terms of sheer numbers available as well as the skills required) in the public sector and is often irrationally distributed ${ }^{2}$. Health emergencies and disasters would keep throwing the health workforce in stress. The numerous challenges faced by $\mathrm{HRH}$ eventually affect the health service delivery and population health outcomes. This is certainly not the last pandemic ${ }^{3}$ we would witness; but, it is important to continuously learn from it and prepare adaptive health systems that function effectively during and post crisis. It is hence critical to understand the key challenges faced by HRH during a pandemic and develop a policy to ensure the resilience of health workforce during any future catastrophes.

This article aimed to identify some critical areas needing policy focus that are important to consider when drafting a health workforce policy. We used a two-step process to draw the key areas for policy focus. We, first, developed a 'HRH resilience framework' (Figure 1) to understand the dimensions of health workforce resilience based on a review of the present literature, understanding the existing challenges, as well as learnings, from within India and in other similar settings. We, then conducted a thematic abstraction of key challenges and identified the areas that need an immediate policy focus in order to develop a resilient workforce.

\section{The $\mathrm{HRH}$ resilience framework}

Figure 1 represents an interaction of system-level, organizational and individual factors, that interact to determine the ability of the health workforce to function normally during and after a crisis.

\section{The challenges and efforts about the health workforce management in times of crisis}

1. The abysmally low financing of health services and a chronic shortage of skilled HRH has long defined India's health system

In the South-eastern region, India spends only $1.28 \%$ of GDP from the public system on health ${ }^{4}$ (2017-18), while the Maldives spends about $8 \%$ (2016). In 2016, the Domestic General Government Health Expenditure per capita in the USA was $\$ 8,078$ whilst this figure was a staggering $\$ 16$ in India. Some of the most populous states of India spend lowest per capita. The per capita public health expenditure in Bihar (population of more than 100 million) is about $\$ 7$, which is one of the lowest in the world if Bihar was a country. The poor spending on health, directly translates to a severe shortage of health workforce. India, with an estimated population of 1.32 billion, has only one government allopathic doctor for average 10,926 persons ${ }^{4}$ - 10 times higher than the WHO recommendation of 1:1000 people. Furthermore, some Indian states with the poorest health index ${ }^{5}$, with a pre dominant rural population ${ }^{6}$, have only one doctor serving up to 28,000 people (EAG states) - with a higher concentration ${ }^{7}$ of doctors in urban areas. Only four states have more than the recommended HRH of 44.5 per 10,000 population in India. While Delhi has the highest density of HRH of 67 , Jharkhand has only $7 \mathrm{HRH}$ per 10,000 persons. The low numbers are further complicated by a very skewed distribution of HRH. In 2011, only two out of five doctors were qualified in India, of which almost $75 \%$ were concentrated in urban areas $^{8}$ (against about 66\% Indian population residing in rural areas), and only around $10 \%$ practice in the public sector ${ }^{4}$, which caters to about $30 \%$ of health care services in India. Government health facilities often fail to attract doctors due to poor quality of life, salaries, vertical growth ${ }^{10}$, and job security ${ }^{11}$.

\section{COVID-19 has accentuated the crisis of health service delivery, but exposure of HRH to COVID-19 worsened the situation}

HRH plays a central role in COVID-19 surveillance and management which puts them at a much higher risk of infection. In addition to the pandemic-related work, the HCW are required to continue providing routine health services, which further overburdens them. While there is a lack of clarity on the official numbers of healthcare workers (HCW) testing positive for SARS-CoV-2, unofficial figures report more than 5000 being tested positive in India by July 2020, with more than 2000 in Delhi ${ }^{12}$ alone. At least 196 doctors $^{13}$ have already died due to infection, of which $40 \%$ were general practitioners. Presently, there is no routine testing of $\mathrm{HCW}$ available, and testing is limited to "high risk exposure' ${ }^{14}$ groups. Despite the MoHFW recommending 14-day quarantine for accidental exposure to SARS-CoV-2 for $\mathrm{HCW}$, this period is often curtailed ${ }^{15}$ in many Indian states. In Bihar, a deficit of health workers has forced those testing positive to continue working. Incidentally, Bihar also has a higher death rate $^{16}$ among doctors than other Indian states. Infection amongst HCW has severely affected the management of other diseases due to closing of hospitals ${ }^{17,18}$ and laboratories ${ }^{19}$. Fear of exposure to the virus has led many doctors and nurses 


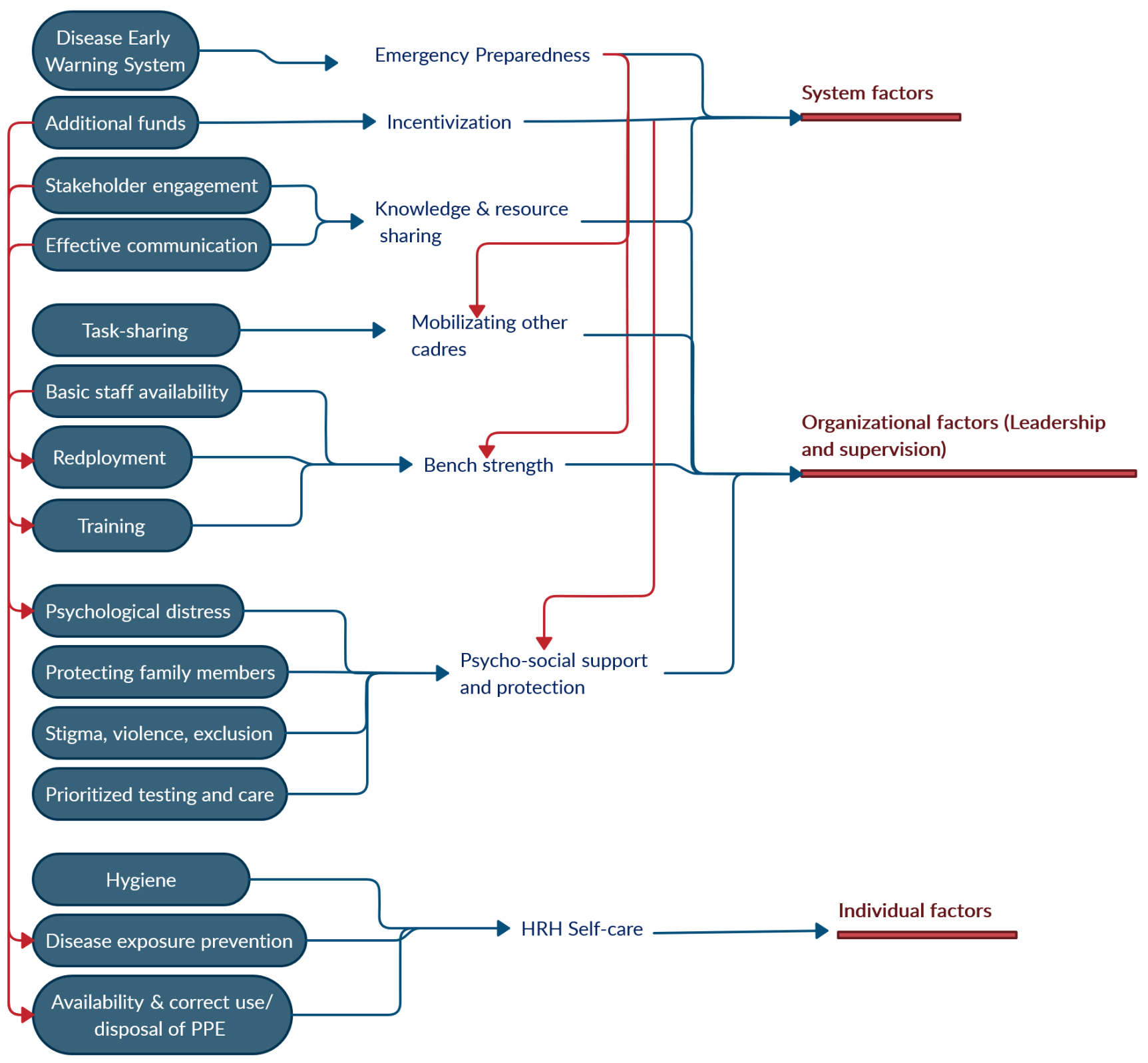

Figure 1. The framework highlights the challenges in a low-resource setting that could be used to inform policies for building early health system planning and preparedness for health emergencies. PPE, Personal protective equipment.

to avoid providing services ${ }^{20}$ in private hospitals, small nursing homes and routine OPD practice at home. This indirectly heightens the burden on the public sector and increases the risk of consultations with informal providers (IP) ${ }^{21}$ in rural areas- which account for $70 \%$ of all rural health service providers- who are insufficiently trained on pandemic management.

Early disease management approaches, such as recruitment of staff and facility-preparedness, has shown success in New Zealand $^{22}$. Also, designing a Disease early warning system (EWS) could prevent worse health outcomes (E.g. Yemen Cholera epidemic $^{23}$ ); however, it could be challenging due to COVID-19 being a respiratory illness. Additionally, having strong public-private partnerships with national and international players $^{24,25}$ and involving them early in the crisis can be beneficial in planning strategies.

3. Indian states with better workforce availability also face novel challenges that were rooted in multiple systemic constrains

Maharashtra, one of the worst affected state, had to resource nurses and doctors from Kerala ${ }^{26}$. Many states are recruiting 
final year medical students to meet doctor shortages. Uttar Pradesh is also facing a decline in the number of doctors due to retirement ${ }^{27}$ in addition to $\mathrm{HCW}$ being infected. Staff deficiency has led Maharashtra to mandate private doctors to work on COVID-19, with failure to do so possibly resulting in revoking their license ${ }^{28}$. The existing health workforce is constrained with additional pressure of working continuously in PPE kits, and no rest-breaks for longer working hours. Inadequate provision of PPE for sample collection and treatment ${ }^{29,30}$ had forced the HRH to wear HIV kits or raincoats and helmets. The public facility doctors $^{31}$ are further strained by private sector, which have the majority beds and ventilators, only handling one in 10 critical cases.

Countries such as the USA and Italy are addressing staff shortage by recruiting new $\mathrm{HCW}^{32}$, medical volunteers, retired professionals, redeployment of existing $\mathrm{HRH}$ to different departments, focus on telemedicine and home-care ${ }^{33}$. As most of the COVID-19 symptoms can be assessed virtually and do not require hospital admission, strengthening CHW and mobilizing other cadres $^{34,35}$ can play a pivotal role especially in rural areas.

\section{The psycho-social impact of COVID-19 further stresses the health workforce}

A survey conducted on $\mathrm{HCW}^{36}$ working directly on COVID-19 management observed higher depressive symptoms and anxiety, with women at greater risk. There were reported suicides and accidents ${ }^{37}$ among HCW due to stigma and fatigue, respectively. Moreover, health workers like doctors, nurses and outreach workers have been subjected to heightened verbal and physical violence, and sexual abuse ${ }^{38}$, including instances of being spat on $^{39}$, accusations of spreading COVID-19 in the community, and having their bags snatched ${ }^{40}$. Many HCW fear infecting their families and social exclusion ${ }^{41}$. Unlike past health emergencies, COVID-19 has established social media ${ }^{42}$ as a perfect medium for rapid transmission of misinformation, stirring mass hysteria in the population, leading to increased attacks on HCW. The motivation of HCW is further reduced by depriving them of timely monthly salaries and implementing pay-cuts ${ }^{43,44}$. In Kerala, poor salary forced about $85 \%$ newly appointed doctors to resign ${ }^{45}$.

\section{Key components for a health workforce resilience policy in low-resourced settings}

Since India and many other countries do not have formal and comprehensive policies for health workforce augmentation, mobilization, motivation and support during extended periods of extensive shocks such as pandemics, policy frameworks to address these gaps are urgently required. Within the federal country structures, provincial policies may also be needed. The interplay of multitude rational, political and contextual factors in drafting such policies should be considered. However, there are some critical components, which almost universally form the part of $\mathrm{HRH}$ resilience policy. Based on the conceptual framework for $\mathrm{HRH}$ resilience (Figure 1) and the challenges mentioned above, we have arrived at these components. The following components aim to address gaps of planning, staff shortage, HRH motivation, and strategic actions. These would need further expansion to draft detailed policy, nevertheless, they provide critical areas of focus for effective and efficient actions to strengthen the health workforce.

i. Emergency preparedness planning including early planning and building health facility readiness

ii. Identification of bench strength of health workforce and upskilling them (e.g. Kerala's initial steps during COVID-19 ${ }^{46}$ ) such as including retired workers, students, non-practicing workers, etc.

iii. Mobilization of health workforce from private to public sector or vice-versa, and to outbreak zones (hot spots). Redeployment of non-health community workers for health-related activities; task-sharing with trained $\operatorname{IPs}^{47}$ (e.g. Liver Foundation, West Bengal).

iv. Incentivization mechanisms for health workforce utilized for pandemic response or exposed to risk (E.g. provision of 'risk allowance')

v. Knowledge and resource sharing by engaging stakeholders

vi. Protection of the HRH and their family from being infected, violence, social exclusion, and support for priority detection and treatment of illness ${ }^{48}$.

vii. Psycho-social support for good mental health and wellbeing (online support, protective measures ${ }^{49}$, and set of individual and organizational measures ${ }^{50}$. Maintaining the motivation of the HRH must be prioritized. Learning from the past Ebola epidemic in Sierra Leone, provision of 'risk allowance' to the $\mathrm{HRH}^{51}$, training/workshops including components of psychosocial support, coping strategies using social media and religious activities could be useful. Targeted interventions building motivation of the workers by addressing their concerns of pay, worklife balance, provisions for families, and timely communication of guidelines would be helpful ${ }^{52}$.

viii. HRH self-care, including making available adequate protective gears

\section{Conclusions}

The acute and persistent shocks on the health systems are not new, but are intensified during outbreaks such as Ebola, SARS, MERS and COVID-19. The health systems at local, national and global levels have fallen short of adequate policy needs and their execution, to remain buoyant during and after such shocks. The health workforce suffers from crises both as citizens and service providers. The increased burden and risk to health workers need to be anticipated and mitigated in advance. This certainly requires policy support at levels of the health system. The HRH resilience framework provided above, and the key components suggested for informing HRH resilience policies, would provide an important start to make further strides in this direction. We call for a multi-stakeholder approach, with a 
shared common objective, to frame and implement such policy, with equitable participation of the health workforce in the development of such policy. We further call for more debate and consultations to make this work further useful and contextual.

\section{Data availability}

No data are associated with this article.

\section{Acknowledgements}

We thank Sudha Ramani for offering insights on the structure of the article. We also thank our colleagues at Oxford Policy Management (Tom Newton Lewis) and BMGF (Priya Nanda) for general ideation, discussions and insights on health systems and resilience-building linked with other studies.

\section{References}

1. India Coronavirus: $\mathbf{6 , 1 4 8 , 6 4 0}$ Cases and $\mathbf{9 6 , 3 7 8}$ Deaths - Worldometer. [cited 2020 Sep 29].

Reference Source

2. Karan A, Negandhi $\mathrm{H}$, Nair $\mathrm{R}$, et al:: Size, composition and distribution of human resource for health in India: new estimates using National Sample Survey and Registry data. BMJ Open. 2019 [cited 2020 Sep 22]; 9(4): e025979. PubMed Abstract | Publisher Full Text | Free Full Text

3. 5 reasons why pandemics like COVID-19 are becoming more likely | Gavi, the Vaccine Alliance. [cited 2020 Sep 16]. Reference Source

4. National Health Profile (NHP) of India- 2019 :: Ministry of Health and Family Welfare. [cited 2020 Sep 16].

Reference Source

5. Aayog N: HEALTHY STATES PROGRESSIVE INDIA Report on the Ranks of States and Union Territories HEALTH INDEX. 2019.

Reference Source

6. NATIONAL FAMILY HEALTH SURVEY (NFHS-4) 2015-16 INDIA. 2017. Reference Source

7. Thayyil J, Jeeja MC: Issues of Creating a new Cadre of Doctors for Rural India. Int J Med Public Heal. 2013; 3(1): 8-11. Publisher Full Text

8. Rao KD, Shahrawat R, Bhatnagar A: Composition and distribution of the health workforce in India: estimates based on data from the National Sample Survey. WHO South East Asia J Public Health. 2016; 5(2): 133-140. PubMed Abstract | Publisher Full Text

9. Rural population (\% of total population) | Data. [cited 2020 Sep 16]. Reference Source

10. Sharma DC: India still struggles with rural doctor shortages. Lancet. 2015 [cited 2020 Sep 16]; 386(10011): 2381-2. PubMed Abstract | Publisher Full Text

11. Purohit $B$, Martineau $T$ : Issues and challenges in recruitment for government doctors in Gujarat, India. Hum Resour Health. 2016 [cited 2020 Sep 16]; 14(1): 43.

PubMed Abstract | Publisher Full Text | Free Full Text

12. Delhi: More Than 2,000 Healthcare Workers Have Tested Positive for COVID-19, Finds Report. [cited 2020 Sep 16].

Reference Source

13. IMA says nearly 200 doctors in India have succumbed to COVID-19 so far; requests PM's attention - The Economic Times. [cited 2020 Sep 16]. Reference Source

14. MoHFW: Advisory for managing Health care workers working in COVID and Non-COVID areas of the hospital. Reference Source

15. India does not test healthcare workers regularly, risking them \& patients | Business Standard News. [cited 2020 Sep 16]. Reference Source

16. Death rate among doctors due to Covid far more in Bihar, says IMA official - india news - Hindustan Times. [cited 2020 Sep 16]. Reference Source

17. 2 Odisha cancer care hospitals shut over Covid exposure, patients in limbo - india news - Hindustan Times. [cited 2020 Sep 16]. Reference Source

18. Staff testing Covid-positive force Bihar private hospitals to shut doors on non-Covid patients. [cited 2020 Sep 16]. Reference Source

19. COVID-19: Laboratories in Bihar's top three health institutes shut after virus spreads among doctors, health workers | India - Gulf News. [cited 2020 Sep 16]. Reference Source

20. Private hospitals in Kolkata struggle with truant doctors | Kolkata News Times of India. [cited 2020 Sep 16] Reference Source
21. Mobilising informal healthcare providers in India may help its response to covid-19 - The BM]. [cited 2020 Sep 16] Reference Source

22. New Zealand takes early and hard action to tackle COVID-19. [cited 2020 Sep 16]. Reference Source

23. Dureab F, Ismail O, Müller O, et al.: Cholera Outbreak in Yemen: Timeliness of Reporting and Response in the National Electronic Disease Early Warning System. Acta Inform Med. 2019 [cited 2020 Sep 16]; 27(2): 85-8. PubMed Abstract | Publisher Full Text | Free Full Text

24. Roy B: How Reforms are Reorienting Public Sector Hospitals in India. ICPP. $2017 ; 3$. Reference Source

25. Chen L, Evans T, Anand S, et al.: Human resources for health: overcoming the crisis. Lancet. 2004; 364(9449): 1984-90. PubMed Abstract | Publisher Full Text

26. Fear Of Infection, Poor Salary Among Reasons Why Nurses Unwilling To Work; Maharashtra has 1.25 lakh nurses, yet shortage continues | India News, The Indian Express. [cited 2020 Sep 16]. Reference Source

27. In Uttar Pradesh, doctors grapple with triple challenge in war against Covid-19 - india news - Hindustan Times. [cited 2020 Sep 16] Reference Source

28. Maharashtra govt issues notification making it mandatory for private doctors in Mumbai to treat COVID-19 patients. [cited 2020 Sep 16]. Reference Source

29. Lab technician's demise raises questions on safety- The New Indian Express. [cited 2020 Sep 16]. Reference Source

30. Shortage of safety equipment crippling states' Covid-19 containment efforts - india news - Hindustan Times. [cited 2020 Sep 16]. Reference Source

31. Covid fight: Govt system in front, private hospitals do the distancing | India News,The Indian Express. [cited 2020 Sep 16] Reference Source

32. Coronavirus cases are pushing Italy's hospitals to the brink | Fortune. [cited 2020 Sep 16] Reference Source

33. COVID-19 response handicapped by staff shortages across rich world CSMonitor.com. [cited 2020 Sep 16]. Reference Source

34. Perry HB, Dhillon RS, Liu A, et al.: Community health worker programmes after the 2013-2016 Ebola outbreak. Bull World Health Organ. 2016 [cited 2020 Sep 16]; 94(7): 551-3. PubMed Abstract | Publisher Full Text | Free Full Text

35. Chersich MF, Gray G, Fairlie L, et al.: COVID-19 in Africa: care and protection for frontline healthcare workers. Bull World Health Organ. 2020 [cited 2020 Sep 16]; 16(1): 46. PubMed Abstract | Publisher Full Text | Free Full Text

36. Wilson W, Raj JP, Rao S, et al.: Prevalence and Predictors of Stress, anxiety, and Depression among Healthcare Workers Managing COVID-19 Pandemic in India: A Nationwide Observational Study. Indian 」 Psychol Med. 2020 [cited 2020 Sep 16]; 42(4): 353-8. Publisher Full Text

37. IMA data shows Covid-19 killed 106 doctors in India till April 15. [cited 2020 Sep 16]. Reference Source

38. Ln S: COVID-19: A "Violent" pandemic for health care workers in India. Publisher Full Text

39. 'We face racism, people spit on us': Over 350 nurses in Kolkata resign, head back to Manipur India News. [cited 2020 Sep 16]. Reference Source 
40. Stigma Against Frontline Health Workers Who Are Working At the Community Level to Tackle COVID-19 Daily in India, Struggles of ASHAs, ANMs \& Field Workers. [cited 2020 Sep 16].

Reference Source

41. Indian doctors being evicted from homes over coronavirus fears World news The Guardian. [cited 2020 Sep 16] Reference Source

42. Covid-19: India's frontline heroes come under attack as rumours, fake news spread on WhatsApp The Star. [cited 2020 Sep 16]. Reference Source

43. 4 states have not made timely payment to Covid-19 healthcare workers: Govt tells Supreme Court - india news - Hindustan Times. [cited 2020 Sep 16]. Reference Source

44. Doctors fighting COVID-19 got upto $50 \%$ pay cut - and some of them haven't been paid yet Business Insider India. [cited 2020 Sep 16]. Reference Source

45. More than $\mathbf{8 0}$ per cent of newly qualified doctors in Indian state quit after Covid-19 wage cuts. [cited 2020 Sep 16]. Reference Source

46. Responding to COVID-19 - Learnings from Kerala. [cited 2020 Sep 16] Reference Source

47. Das J, Chowdhury A: The impact of training informal health care providers in India: A randomized controlled trial. Reference Source

48. Adams JG, Walls RM: Supporting the Health Care Workforce during the COVID-19 Global Epidemic. JAMA American Medical Association; 2020 [cited 2020 Sep 16]; 323: 1439-40.

PubMed Abstract | Publisher Full Text

49. Preti E, Di Mattei V, Perego G, et al.: The Psychological Impact of Epidemic and Pandemic Outbreaks on Healthcare Workers: Rapid Review of the Evidence. Curr Psychiatry Rep Springer; 2020 [cited 2020 Sep 16]; 22(8): 43. PubMed Abstract | Publisher Full Text | Free Full Text

50. Heath C, Sommerfield A, von Ungern-Sternberg BS: Resilience strategies to manage psychological distress among healthcare workers during the COVID-19 pandemic: a narrative review. Anaesthesia. 2020 [cited 2020 Sep 16]; 75(10): 1364-1371.

PubMed Abstract | Publisher Full Text | Free Full Text

51. Raven J, Wurie H, Witter S: Health workers' experiences of coping with the Ebola epidemic in Sierra Leone's health system: A qualitative study. BMC Health Serv Res. 2018 [cited 2020 Sep 16]; 18(1): 251. PubMed Abstract | Publisher Full Text | Free Full Text

52. Factors that influence whether healthcare workers follow infection prevention and control guidelines for respiratory infectious diseases Cochrane. [cited 2020 Sep 16].

Reference Source 


\section{Open Peer Review}

\section{Current Peer Review Status: $\checkmark$ ? ?}

Version 1

Reviewer Report 11 February 2021

https://doi.org/10.21956/gatesopenres.14402.r30293

(C) 2021 N Srinivas P. This is an open access peer review report distributed under the terms of the Creative Commons Attribution License, which permits unrestricted use, distribution, and reproduction in any medium, provided the original work is properly cited.

\section{Prashanth N Srinivas \\ Health Equity Cluster, Institute of Public Health, Bengaluru, India}

Thank you for the opportunity to review this letter. As an academic communication that seeks to critically engage with the issue of strengthening $\mathrm{HRH}$ from a systems lens, I appreciate the initiative by the authors in communicating this. Given that there is a systematic effort at conceiving a framework and in thematic abstraction that the authors seek to apply to guiding public policy efforts on this topic, I have reviewed it as if it were a commentary (given that this is the first time I am applying a peer review lens to a submission that is titled "open letter") in hope that this is helpful to the authors and the audience. In terms of its readiness for publication as an open letter, I find no basis for needing significant revisions. That said, the comments below are offered to the authors as critical observations/remarks to engage with in case they move forward with the arguments presented.

\section{On India as an "unregulated" health system}

The assertion (in the abstract) that India's health system is "largely unregulated" may need critical examination. While there are huge regulatory gaps in the Indian Health System, I wonder if there is a gold-standard against which to compare/contrast regulation. This is altogether an independent area of inquiry, but without going too deep/far in that line, what I would like to point out is the need to nuance this carefully. For eg. there are aspects of Indian health services (cf. systems) which are reasonably regulated, whereas there are other aspects that are hardly even considered under formal regulatory mechanisms. Furthermore, regulation (or even lack thereof) is often a choice and hence this too ought to guide assessments of descriptions...even more so when health is a state subject and Indian states vary in terms of what aspects they choose to or do not choose to regulate.

\section{On the need for health workforce resilience}

While the need for systemic resilience picks up steam in global and national policy circles, there is also a need to locate this within the wider social and political policy environment within which health policy operates. Is there sufficient demands from within communities/HRH groups for such a move? Who are the prime movers of reforms that shift systems towards greater resilience? How are these being conceived and how ought they to be conceived? These are important/useful 
reflections that such moves in shaping resilience literature in academia could engage with (in terms of critically examining their own positions vis-a-vis resilience building).

\section{On the consequences of a weak HRH capacity}

In the section that outlines the consequences of "India's weak HRH capacity and its inadequate deployment strategies...", authors appear to restrict their consequences only to contentment and spread of pandemic. IT has been widely reported and analysed that this could have also impacted our ability to report numbers adequately. Indeed, states which are likely to have better-off $\mathrm{HRH}$ deployment did report more numbers (cf. Kerala). This could also have contributed to the overall low mortality and positive numbers from India even if it does not entirely explain this.

\section{On the focus on the "immediate"}

By choosing to focus on the "immediate", I wonder if the authors neglect possible components that could have been conceptualised only if they had envisioned a medium to long-term as well? This may be a limitation of the lens they apply.

\section{On the framework}

I am a bit confused as to whether Figure 1 is a framework that they begin with or that they arrive at? (Or neither?). How did they choose which ones to include and which ones not and how did they determine the linkages? For eg. previous commitment and motivation of staff is an important input as to how they may respond to pandemics. Overall trust in public services (vs private healthcare sector) too is an important environmental determinant of how health systems perform (or don't) during pandemics but they do not figure here. And a comprehensive scoping of academic literature on resilience (or consultations with health workers themselves or with communities) may yield other relationships/linkages that are not captured here. I understand that the aim is not to develop a comprehensive framework, but figure 1's description may have to be sharpened for it to be described as precisely as possible.

\section{On broadening the application of key elements of the framework}

In the section on abysmally low financing authors pre-dominantly deal with $\mathrm{HRH}$ availability and appear to indicate that this is directly and probably the only(? They do not talk about any other and hence this inference). But HRH distribution and availability can be a problem even in wellfinanced health systems. I am not clear as to why they focus on $\mathrm{HRH}$ mal-distribution and availability to illustrate financing. I agree that availability may improve with financing, but it may not as well. In fact as they point out various other social and political factors, pre-dominantly at state level too determine these. Doctor/nurse/health worker unions too often safeguard their own interest and hence some of these are related to the wider political economy of availability and not only to financing in my opinion. While many of these may be outside the scope of the letter, there must be some engagement/acknowledgement of these in the narrative in my opinion.

\section{On public-private partnerships}

Evidence is quite mixed in favour and/or against possible PP arrangements, certainly with "national and international players". On the other hand policy initiatives to push forward PPPs in health have been mired not only in technical debates but also in debates related to conflicting interests, lack of accountability, poor ability of the State to safeguard the "public" in such arrangements etc. I understand again that this may be outside the scope of the letter but this will need to be engaged with critically to represent multiple views on this in my opinion. 


\section{Is the rationale for the Open Letter provided in sufficient detail? \\ Yes}

Does the article adequately reference differing views and opinions?

Partly

\section{Are all factual statements correct, and are statements and arguments made adequately supported by citations? \\ Yes}

Is the Open Letter written in accessible language?

Yes

Where applicable, are recommendations and next steps explained clearly for others to follow?

Yes

Competing Interests: No competing interests were disclosed.

Reviewer Expertise: Health policy and systems research especially on health inequities and social determinants of health, OneHealth and intersectional action for health, evaluation of HRH interventions

I confirm that I have read this submission and believe that I have an appropriate level of expertise to confirm that it is of an acceptable scientific standard, however I have significant reservations, as outlined above.

Reviewer Report 08 February 2021

https://doi.org/10.21956/gatesopenres.14402.r30292

(C) 2021 Mash R. This is an open access peer review report distributed under the terms of the Creative Commons Attribution License, which permits unrestricted use, distribution, and reproduction in any medium, provided the original work is properly cited.

\section{Robert Mash}

Division of Family Medicine and Primary Care, Stellenbosch University, Cape Town, South Africa

This article presents a resilience framework for human resources for health, discusses four key issues with regard to the Indian workforce and responding to COVID-19 and finally makes a series of recommendations for the development of future policy on responding to disasters or pandemics.

Key concepts used in the article need to be defined at the beginning or when first used. For example what is meant by resilience? What is meant by bench strength? 
The resilience framework presents 15 items that are mapped onto 7 intermediate constructs and finally three constructs at the system, organizational and individual levels. The methods and literature used to construct this framework are given only cursory attention and the rationale for the items and relationships portrayed in the framework are not elaborated. Was there a scoping review for example and if so what are the details of this? Explain the framework to the reader. For the reader to accept the validity of the framework and to understand it, both of these issues need to be tackled.

It is said that the literature was from India and similar settings, however the other countries mentioned are New Zealand, USA and Italy. I am not sure that these can be considered similar settings.

The four key issues that are discussed are said to be a 'thematic abstraction' from this framework. What exactly this means is not clear. The conceptual links to the framework are not explained and the framework itself and the four key issues appear to be unrelated to each other and to a large extent stand-alone from each other in the article.

The final list of recommendations for policy are interesting and probably make sense. However they do not obviously all flow from the four key issues and the resilience framework. Again there is a disconnect for the reader. As far as I can understand it the logical flow of the article is (1) a resilience framework for $\mathrm{HRH}$ was constructed from the literature. (2) key issues were abstracted from this framework (3) policy recommendations were derived from these key issues. The linkages between these components and the logical flow need to be more explicit.

There are numerous grammatical and linguistic issues in the article which I have made note of in this file.

Is the rationale for the Open Letter provided in sufficient detail?

Yes

Does the article adequately reference differing views and opinions?

Partly

Are all factual statements correct, and are statements and arguments made adequately supported by citations?

No

Is the Open Letter written in accessible language?

Partly

Where applicable, are recommendations and next steps explained clearly for others to follow?

Partly

Competing Interests: No competing interests were disclosed.

Reviewer Expertise: Family medicine, primary health care, health services and chronic diseases. 


\section{I confirm that I have read this submission and believe that I have an appropriate level of expertise to confirm that it is of an acceptable scientific standard, however I have significant reservations, as outlined above.}

Reviewer Report 03 December 2020

https://doi.org/10.21956/gatesopenres.14402.r30044

(c) 2020 Cometto G. This is an open access peer review report distributed under the terms of the Creative Commons Attribution License, which permits unrestricted use, distribution, and reproduction in any medium, provided the original work is properly cited.

\section{Giorgio Cometto}

Health Workforce Department, World Health Organization, Geneva, Switzerland

I would like to congratulate the authors for this interesting submission. I would encourage the authors to provide additional details if available on the results/impact of the policy

recommendations made.

I would also encourage them to review and consider the recommendations in the WHO guidance on health workforce policy and management in the context of COVID-19, which adopts a similar framework and provides many similar policy recommendations.

Another useful reference to consider in your bibliography is the similarly related paper (but taking a global overview) by Ivy Bourgeault in the HRH Journal ${ }^{1}$. But very supportive of this manuscript being indexed.

\section{References}

1. Bourgeault I, Maier C, Dieleman M, Ball J, et al.: The COVID-19 pandemic presents an opportunity to develop more sustainable health workforces. Human Resources for Health. 2020; 18 (1). Publisher Full Text

Is the rationale for the Open Letter provided in sufficient detail?

Yes

Does the article adequately reference differing views and opinions? Yes

Are all factual statements correct, and are statements and arguments made adequately supported by citations?

Yes

Is the Open Letter written in accessible language?

Yes

Where applicable, are recommendations and next steps explained clearly for others to 
follow?

Yes

Competing Interests: No competing interests were disclosed.

Reviewer Expertise: Health systems - human resources for health

I confirm that I have read this submission and believe that I have an appropriate level of expertise to confirm that it is of an acceptable scientific standard. 